\title{
Chiral Cp Ligands in Rhodium-Catalyzed Asymmetric C-H Functionalization
}

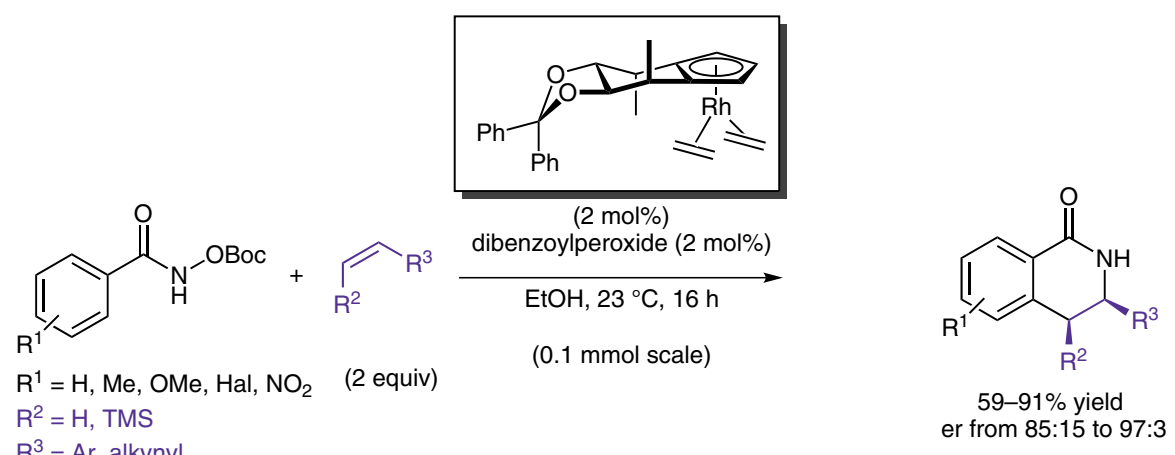

Selected examples:<smiles></smiles>

$70 \%$ yield er $=92: 8$

Postulated model for stereoinduction:<smiles>O=C1NC(c2ccccc2)Cc2cc(F)ccc21</smiles>

\section{$81 \%$ yield} er $=96: 4$

Me group orients substrate

\section{Category}

Metal-Catalyzed

Asymmetric

Synthesis and

Stereoselective

Reactions

\section{Key words}

rhodium

chiral

cyclopentadienyl

ligands

isoquinolones

asymmetric C-H

functionalization

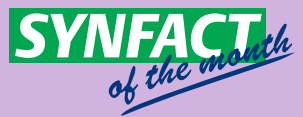

Significance: A rhodium complex with a chiral $\mathrm{Cp}$ ligand that catalyzes an enantioselective synthesis of isoquinolones via a directed $\mathrm{C}-\mathrm{H}$ bond functionalization is reported. Often, in half-sandwich transition-metal-catalyzed reactions, Cp remains the sole permanent ligand on the metal. Thus, despite the challenges, the development of chiral $\mathrm{Cp}$ ligands for inducing enantioselectivity is a powerful approach.
Comment: The highly effective Cp ligand reported is postulated to control the spatial orientation of the coupling partners. For instance, the ligand is $\mathrm{C}_{2}$-symmetric to avoid diastereomeric coordination of the metal. The benzophenone ketal shields one face of the substrate and the equatorial methyl group pushes the bulky Boc group away. The controlled trajectory of the attacking alkene gives rise to the stereo-configuration of the product. 